\title{
Prediction of Cerebral Vasospasm Using Early Stage Transcranial Doppler
}

\author{
Hiroyuki TOI, ${ }^{1}$ Noriko MATSUMOTO, ${ }^{2}$ Kimihiko YOKOSUKA, ${ }^{1}$ \\ Shunji MATSUBARA, ${ }^{1}$ Kazuhiro HiRANO, ${ }^{1}$ and Masaaki UNO ${ }^{1}$ \\ Departments of ${ }^{1}$ Neurosurgery and ${ }^{2}$ Stroke Medicine, \\ Kawasaki Medical School, Kurashiki, Okayama
}

\begin{abstract}
Transcranial Doppler (TCD) is widely used to monitor vasospasm after subarachnoid hemorrhage (SAH), but its ability to predict the future occurrence of the symptomatic vasospasm (SVS) remains controversial. We investigated the utility of TCD for predicting the future occurrence of SVS after SAH in 45 patients with aneurysmal SAH. TCD was performed on days $1,3,5,7,10$, and 14 after SAH. The mean flow velocity (MFV) of the horizontal portion of the middle cerebral artery $\left(M_{1}\right)$ was recorded. SVS occurred in $24.4 \%$ of patients $(n=11)$. MFV of $M_{1}$ increased progressively in patients with SVS, but did not increase in patients without SVS. The mean MFV values were significantly higher in patients with SVS than in patients without SVS $(p=0.031)$. The mean MFV value on day 3 was already significantly higher in patients with SVS than in patients without SVS $(88.5 \mathrm{~cm} / \mathrm{sec}$ versus $62.7 \mathrm{~cm} / \mathrm{sec}$, respectively) $(p=0.018)$. The receiver operating characteristic curve of MFV on day 3 showed the threshold of 72.5 $\mathrm{cm} / \mathrm{sec}$ for predictive value of SVS in the future (sensitivity $71.4 \%$, specificity $68.1 \%$, and accuracy $\mathbf{8 2 . 3 \%}$ ). Increased MFV of $M_{1}$ during the early stage of SAH may predict the future occurrence of SVS. The threshold value of $72.5 \mathrm{~cm} / \mathrm{sec}$ MFV of $M_{1}$ on SAH day 3 was one of the best predictor of future SVS. To prevent delayed cerebral ischemia, aggressive treatment for vasospasm is needed for patients with increased MFV in the early stages of SAH.
\end{abstract}

Key words: subarachnoid hemorrhage, vasospasm, transcranial Doppler, mean flow velocity, prediction

\section{Introduction}

Symptomatic vasospasm (SVS) is a serious complication of aneurysmal subarachnoid hemorrhage $(\mathrm{SAH}){ }^{27)}$ Poor outcome is associated with the development of neurological deterioration associated with cerebral vasospasm, which can be detected on angiography in $70 \%$ of patients with ruptured intracranial aneurysms. ${ }^{6,7,12)}$ SVS develops between SAH post-bleed days 3 and 14 , and $20 \%$ to $40 \%$ of patients will develop neurological deficits or infarction caused by delayed cerebral ischemia. ${ }^{4,21,23,28,32)} \mathrm{A}$ strong association exists between angiographic vasospasm and cerebral infarction.5)

Conventional angiography is the most accurate and reliable method for vasospasm detection. However, cerebral angiography is invasive and carries some risks, making serial examinations impossi-

Received September 7, 2012; Accepted January 17, 2013 ble to perform. ${ }^{16)}$ The introduction of transcranial Doppler (TCD) in 1982 has provided a noninvasive approach for the evaluation of cerebral vasospasm and for monitoring the development and resolution of this condition. ${ }^{1,2,9,24)}$ Acceleration of TCD mean blood flow velocity (MFV) to more than $120 \mathrm{~cm} / \mathrm{sec}$ provides approximately $80 \%$ sensitivity and specificity for the presence of angiographic vasospasm in the proximal middle cerebral artery (MCA). ${ }^{20)}$ At present, TCD is the most widely used imaging modality for diagnosing vasospasm. ${ }^{33)}$ Nevertheless, TCD has not been evaluated for predicting the future development of SVS.

The present study investigated the utility of TCD for predicting future development of SVS during the early stages after SAH and to derive the threshold using a statistical approach.

\section{Materials and Methods}

Subjects were 98 consecutive patients with aneurys- 
mal SAH admitted to the Neurological Intensive Care Unit of Kawasaki Medical School, between April 2009 and March 2011. The diagnosis of aneurysmal SAH was established on the basis of admission computed tomography (CT) and angiography. Exclusion criteria included secondary SAH from trauma, arteriovenous malformation, mycotic aneurysms, unknown origin, or other causes, age younger than 18 years, death on or before SAH day 4 (because of the low risk of developing vasospasm), admission 4 days after $\mathrm{SAH}$ onset, and lack of adequate TCD windows. The study was approved by the hospital Institutional Review Board. Informed consent was obtained from the patients or their family. This study was registered in the University Hospital Medical Information Network (Application number 20110412-235241).

All patients underwent digital subtraction angiography on admission. Selection of treatment with clipping or endovascular coil embolization resulted from a consensus reached between the treating neurosurgeon and the interventional neuroradiologist after analyzing the risks and chances of success of both therapeutic modalities for each particular case. All patients received $0.9 \%$ normal saline at a rate of $1 \mathrm{ml} / \mathrm{kg}$ per hour and an appropriate dosage of supplemental $5 \%$ albumin solution was administered to maintain positive fluid balance and central venous pressure $>5 \mathrm{mmHg}$. All patients received intravenous fasudil hydrochloride every 8 hours from day 4 to day 14 . Oral statin and mineral corticoid were not routinely administered. Persistent fever (temperature exceeding $38.5^{\circ} \mathrm{C}$ ) was treated with acetaminophen and surface cooling devices. Angiography was routinely performed on patients in whom SVS developed. Endovascular treatment of vasospasm entailed either intra-arterial chemical vasodilation with fasudil hydrochloride or balloon angioplasty. The decision to perform endovascular intervention was made at the discretion of the neurosurgeons and stroke physicians.

SVS was defined as the development of new focal neurological signs, deterioration of the level of consciousness, or both, when the cause was felt to be ischemia attributable to vasospasm after other possible causes of worsening (for example, hydrocephalus, intracranial hemorrhage, focal brain swelling, seizures, infection, hyponatremia) had been excluded. The diagnosis of SVS was adjudicated on the basis of consensus of the study team. Angiographic vasospasm was defined as moderate-to-severe arterial narrowing on digital subtraction angiography not attributable to atherosclerosis, catheter-induced spasm, or vessel hypoplasia.

TCD was performed on SAH days $1,3,5,7,10$, and 14 by the independent stroke physician (N.M.) who was not involved in the operation, but who was well-acquainted with TCD examination. The data on SAH day 1 were obtained before the clinical highrisk period for vasospasm, and were used as the baseline for comparison with further TCD examinations. Recordings of the MFV of the horizontal part of the MCA $\left(\mathrm{M}_{1}\right)$ were measured through the transtemporal windows using a $2-\mathrm{MHz}$ handheld transducer probe. Using the transtemporal window, the depth of insonation varied between 50 and $60 \mathrm{~mm}$ for evaluation of the MCA. The MFV, peak systolic velocity, end-diastolic velocity, and pulsatility index of $\mathrm{M}_{1}$ were recorded for each TCD examination. The Lindegaard index was not calculated because cervical internal carotid artery velocities were not routinely recorded.

Data analyses were performed with commercially available statistics software (SPSS version 12.0; SPSS Inc., Chicago, Illinois, USA). Chi-square analysis was used to test associations between categorical variables. A two-way repeated measures analysis of variance (ANOVA) was calculated to test for differences in the MFV of $M_{1}$ between the group that developed SVS and the group that did not develop SVS. A Mann-Whitney $U$ test was used for non-normally distributed continuous variables. The significance level was set at $p<0.05$. Receiver operating characteristic (ROC) curves were developed, and the area under the curve was calculated to evaluate the value of MFV of $M_{1}$ thresholds for predicting future SVS.

\section{Results}

Forty-five of the 98 patients with aneurysmal SAH were included in the present analysis. The most common reason for patient exclusion was the lack of adequate TCD windows. Among the 98 patients with aneurysmal SAH, 32 patients were excluded because of inadequate windows (representing $32.7 \%$ of all patients with aneurysmal SAH). The 45 patients who met all of the inclusion criteria were 13 men $(28.9 \%)$ and 32 women $(71.1 \%)$. The mean age was $61.9 \pm$ 15.2 years.

SVS occurred in 11 of the 45 patients (24.4\%). Arterial vasospasm was diagnosed with angiography in all of these patients. The median interval from SAH onset to the diagnosis of SVS was 7.36 days (range 2 to 12 days). Endovascular treatment for vasospasm was performed in 9 of 11 patients with SVS. Clinical characteristics of patients with and without SVS are compared in Table 1. No clinical or radiological variables were associated with SVS at admission.

TCD examinations performed on or before SAH day 14 were analyzed. MFV of $\mathrm{M}_{1}$ in patients with 
Table 1 Characteristics of patients with and without symptomatic vasospasm (SVS)

\begin{tabular}{|c|c|c|c|c|}
\hline & Overall $(n=45)$ & No SVS $(n=34)$ & $\operatorname{SVS}(\mathrm{n}=11)$ & $\mathrm{p}$ Value \\
\hline \multicolumn{5}{|l|}{ Demographics: } \\
\hline Age (yrs) & $61.9 \pm 15.2$ & $62.4 \pm 16.5$ & $60.3 \pm 10.6$ & 0.492 \\
\hline Male & $13(28.9 \%)$ & $10(29.4 \%)$ & $3(27.3 \%)$ & 0.892 \\
\hline \multicolumn{5}{|l|}{ Admission clinical: } \\
\hline Hunt and Hess grade & & & & 0.904 \\
\hline I & 5 & 2 & 1 & \\
\hline II & 17 & 14 & 2 & \\
\hline III & 9 & 6 & 3 & \\
\hline IV & 11 & 5 & 2 & \\
\hline $\mathrm{V}$ & 3 & 1 & 1 & \\
\hline \multicolumn{5}{|l|}{ Admission radiological: } \\
\hline Aneurysm location & & & & 0.728 \\
\hline ACoA & 15 & 13 & 2 & \\
\hline distal ACA & 6 & 4 & 2 & \\
\hline $\mathrm{AChA}$ & 3 & 2 & 1 & \\
\hline PCoA & 11 & 8 & 3 & \\
\hline MCA & 8 & 5 & 3 & \\
\hline others & 2 & 2 & 0 & \\
\hline Aneurysm treatment & & & & 0.838 \\
\hline clip & 29 & 22 & 7 & \\
\hline coil & 12 & 9 & 3 & \\
\hline clip and coil & 2 & 1 & 1 & \\
\hline none & 2 & 2 & 0 & \\
\hline
\end{tabular}

ACA: anterior cerebral artery, AChA: anterior choroidal artery, ACoA: anterior communicating artery, MCA: middle cerebral artery, PCoA: posterior communicating artery.

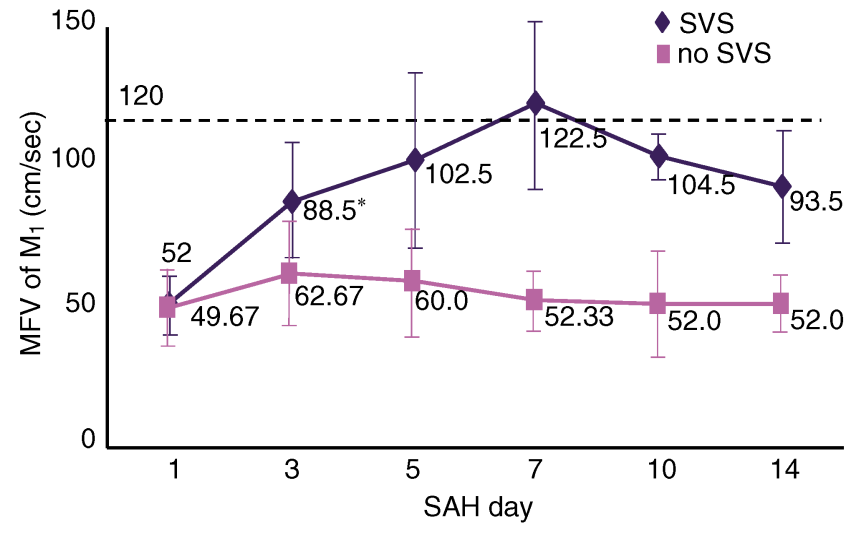

Fig. 1 Evolution of mean flow velocity (MFV) values in patients who did (diamonds) or did not (squares) develop symptomatic vasospasm (SVS) between subarachnoid hemorrhage (SAH) days 3 and 14. MFV of $M_{1}$ in patients with SVS increased progressively between SAH days 3 and 7, whereas MFV of $M_{1}$ in patients without SVS did not increase at any time. Two-way repeated measures analysis of variance showed significant differences in the progress of the MFV of $M_{1}$ between the SVS and no SVS groups $(p=0.031)$. The $M F V$ of $M_{1}$ in the SVS group had already increased significantly on SAH day 3 compared with the no SVS group $\left({ }^{*} p=0.018\right.$, MannWhitney $U$ test).

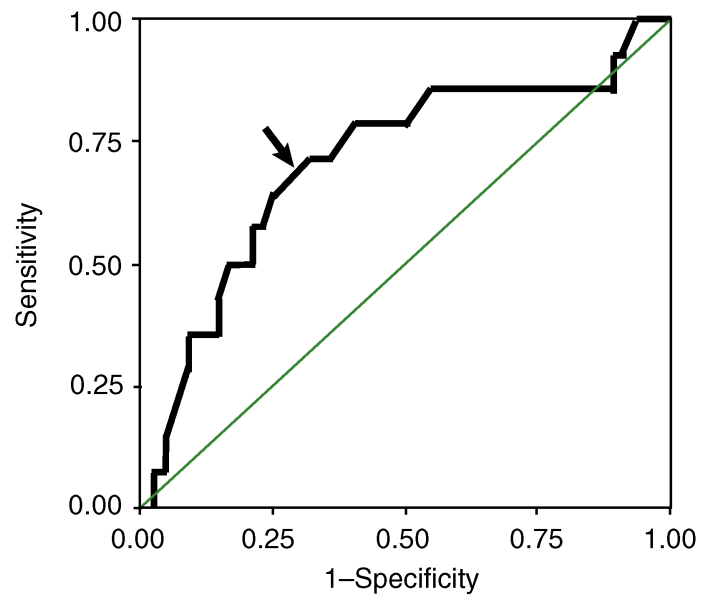

Fig. 2 Receiver operating characteristic (ROC) curve of mean flow velocity of $M_{1}$ on subarachnoid hemorrhage day 3 for the future occurrence of symptomatic vasospasm (SVS). The ROC curve analysis identified the optimal threshold value of $72.5 \mathrm{~cm} / \mathrm{sec}$ (arrow) for predicting the future occurrence of SVS (sensitivity $71.4 \%$, specificity $68.1 \%$, and accuracy $82.3 \%$ ). The area under the curve was 0.71 . 
SVS increased progressively between SAH days 3 and 7 before beginning to decrease, whereas MFV of $\mathrm{M}_{1}$ in patients without SVS did not increase significantly at any time (Fig. 1). The highest MFV of $\mathrm{M}_{1}$ in patients with SVS was found at SAH day 7. A two-way repeated measures ANOVA showed significant differences in the progress of the MFV of $\mathrm{M}_{1}$ between the SVS group and the no SVS group ( $p=0.031$ ) (Fig. 1). The MFV of $M_{1}$ in the SVS group had already significantly increased on SAH day 3 compared with the no SVS group (Mann-Whitney $U$ test, $p=0.018$ ). The high values for the MFV of $M_{1}$ on SAH day 3 predict the future occurrence of SVS. The ROC curve showing the overall diagnostic utility of MFV of $\mathrm{M}_{1}$ on the SAH day 3 for the future occurrence of SVS revealed an area under the curve of 0.71 (Fig. 2). The ROC curve analysis identified the optimal threshold value of $72.5 \mathrm{~cm} / \mathrm{sec}$ for predicting the future occurrence of SVS. The threshold value has a global accuracy of $82.3 \%$, with a sensitivity and specificity of $71.4 \%$ and $68.1 \%$, respectively.

\section{Discussion}

In this study, we found that the TCD value in the early stage of SAH may be used to predict the future occurrence of SVS. We constructed a ROC curve to identify the flow velocities with the greatest sensitivity and specificity for predicting the SVS. The SVS group showed a higher MFV of $M_{1}$ than the no SVS group during the period on or after $\mathrm{SAH}$ day 3, and the threshold of $72.5 \mathrm{~cm} / \mathrm{sec} \mathrm{MFV}$ of $\mathrm{M}_{1}$ on day 3 predicts the future occurrence of SVS. Thus, patients were more likely to suffer from SVS in the

Table 2 Summary of studies documenting the predictors of vasospasm

\begin{tabular}{|c|c|c|c|c|c|c|}
\hline Author (Year) & Study type & $\begin{array}{l}\text { No. of } \\
\text { patients }\end{array}$ & $\begin{array}{l}\text { Predictor for } \\
\text { vasospasm }\end{array}$ & $\begin{array}{c}\text { Diagnostic } \\
\text { device/ } \\
\text { material }\end{array}$ & $\begin{array}{l}\text { Timing of } \\
\text { examination }\end{array}$ & Main findings \\
\hline $\begin{array}{l}\text { Reilly et al. } \\
\quad(2004)^{22)}\end{array}$ & $\begin{array}{l}\text { prospective } \\
\text { observational }\end{array}$ & 75 & $\begin{array}{l}\text { clot volume and } \\
\text { clearance rate }\end{array}$ & CT & on admission & $\begin{array}{l}\text { initial subarachnoid clot } \\
\text { volume and the } \\
\text { percentage of clot cleared } \\
\text { per day predict SVS }\end{array}$ \\
\hline$\underset{(2005)^{10)}}{\text { Hirashima et al. }}$ & retrospective & 100 & $\begin{array}{l}\text { decrease in } \\
\text { platelet count }\end{array}$ & serum & $\begin{array}{l}\text { days } 8-10 \\
\text { after SAH }\end{array}$ & $\begin{array}{l}\text { ratio of the lowest platelet } \\
\text { count and the admission } \\
\text { count greater than } 0.7 \text { is } \\
\text { a predictor of SVS }\end{array}$ \\
\hline $\begin{array}{l}\text { Udoetuk et al. } \\
\qquad(2007)^{30)}\end{array}$ & retrospective & 105 & $\begin{array}{l}\text { cerebral } \\
\text { circulation } \\
\text { time }\end{array}$ & DSA & $\begin{array}{l}\text { within } 24 \mathrm{hrs} \\
\text { after SAH }\end{array}$ & $\begin{array}{l}\text { prolonged CCT within } 24 \\
\text { hrs after SAH is } \\
\text { associated with } \\
\text { subsequent angiographic } \\
\text { vasospasm }\end{array}$ \\
\hline $\begin{array}{l}\text { Fountas et al. } \\
(2009)^{8)}\end{array}$ & retrospective & 41 & CRP levels & $\underset{\text { CSF }}{\operatorname{serum}}$ and & $\begin{array}{l}\text { within } 9 \\
\text { days after } \\
\text { SAH }\end{array}$ & $\begin{array}{l}\text { patients with angiographic } \\
\text { vasospasm had higher } \\
\text { CRP measurements in } \\
\text { serum and CSF }\end{array}$ \\
\hline $\begin{array}{l}\text { Testai et al. } \\
\quad(2011)^{29)}\end{array}$ & $\begin{array}{l}\text { prospective } \\
\text { observational }\end{array}$ & 25 & $\begin{array}{l}\text { circulating } \\
\text { antiangiogenic } \\
\text { factors }\end{array}$ & $\begin{array}{l}\text { sEng and } \\
\text { sFlt1 }\end{array}$ & $\begin{array}{l}\text { within } 48 \mathrm{hrs} \\
\text { after SAH }\end{array}$ & $\begin{array}{l}\text { SVS patients had higher } \\
\text { CSF sEng and sFlt1 } \\
\text { levels within } 48 \text { hrs after } \\
\text { SAH than no-SVS } \\
\text { patients }\end{array}$ \\
\hline $\begin{array}{l}\text { Ibrahim and } \\
\text { Macdonald } \\
(2012)^{11)}\end{array}$ & $\begin{array}{l}\text { prospective } \\
\text { randomized }\end{array}$ & 413 & $\begin{array}{c}\text { prolonged QT } \\
\text { interval and } \\
\text { tachycardia }\end{array}$ & ECG & $\begin{array}{l}\text { within } 48 \mathrm{hrs} \\
\text { after SAH }\end{array}$ & $\begin{array}{l}\text { ECG within } 48 \text { hrs after } \\
\text { SAH predicts } \\
\text { angiographic vasospasm, } \\
\text { not associated with SVS }\end{array}$ \\
\hline $\begin{array}{l}\text { Wilson et al. } \\
(2012)^{34)}\end{array}$ & retrospective & 250 & $\begin{array}{l}\text { maximal SAH } \\
\text { thickness }\end{array}$ & $\begin{array}{l}\text { new scale } \\
\text { using } \\
\text { admission } \\
\text { CT }\end{array}$ & on admission & $\begin{array}{l}\text { new scale using admission } \\
\text { CT predicts SVS }\end{array}$ \\
\hline
\end{tabular}

CCT: cerebral circulation time, CRP: C-reactive protein, CSF: cerebrospinal fluid, CT: computed tomography, DCI: delayed cerebral ischemia, DSA: digital subtraction angiography, ECG: electrocardiography, sEng: soluble endoglin, sFlt1: soluble fms-like tyrosine kinase 1, NIRS: near-infrared spectroscopy, SAH: subarachnoid hemorrhage, SVS: symptomatic vasospasm, TCD: Transcranial Doppler. 
future if the MFV of the $\mathrm{M}_{1}$ on day 3 exceeded 72.5 $\mathrm{cm} / \mathrm{sec}$.

Previous studies have reported some risk factors that predict future SVS, such as high C-reactive protein value, ${ }^{8)}$ extended circulation time on angiography, ${ }^{30)}$ and decrease in platelet count. ${ }^{10)} \mathrm{Re}$ cent reports of predictors of vasospasm are shown in Table $2 .^{3,8,10,11,19,22,29,30,34)}$ In addition, studies have used near-infrared spectroscopy, xenon CT, perfusion CT, and probability index, but many of these methods are detectors of vasospasm, not predictors of vasospasm. These reports showed no clear threshold. In contrast, the present report found a clear threshold for predicting vasospasm.

TCD spasm is often defined as a MFV of 120 $\mathrm{cm} / \mathrm{sec}$, and there is considerable support for this absolute value. ${ }^{2)}$ It is commonly used in the literature when examining the association with angiographic vasospasm or SVS. Recent studies have shown that a rise of the TCD level indicates the existence of angiographical vasospasm in "the point of the time,",13) and a MFV of $120 \mathrm{~cm} / \mathrm{sec}$ indicates the existence of angiographical vasospasm regardless of the number of days from SAH onset. ${ }^{20)}$ However, among the patients with angiographical vasospasm, many do not develop SVS. Thus, prediction of SVS is exceedingly important.

No report has proved the relationship between the MFV of $M_{1}$ in the early stage of SAH and the future occurrence of SVS. The normal diameter of the MCA reported 2.9-3.4 mm, ${ }^{25,31)}$ and MFV is directly correlated with narrowing grade. Indeed, a statistically significant correlation was found between MFV and the angiographic lumen diameter of MCA, and MFV of $72.5 \mathrm{~cm} / \mathrm{sec}$ indicated residual lumen diameter of the MCA of about $2.5 \mathrm{~cm} .{ }^{27)}$ TCD examination has a high enough sensitivity to detect slight changes in the cerebral vessels. TCD may detect a slight narrowing of the vessel diameter due to the vasospasm. In future research, it is necessary to prove the vessel diameter change of a patient with a MFV of $\mathrm{M}_{1}$ over $72.5 \mathrm{~cm} / \mathrm{sec}$ on day 3 using magnetic resonance angiography or digital subtraction angiography. Age difference is known to exist in MFV measured by TCD. In this study, all age groups were statistically analyzed so that results could be generalized to any age group. An age-specific evaluation may allow a more detailed analysis.

Several important limitations of this study deserve emphasis. First, TCD was not performed in all patients with aneurysmal SAH. A lack of adequate TCD windows affected this study. The detection rate of adequate TCD windows was reportedly lower in African-American and Asian groups, and was also lower in older women. ${ }^{15,16)}$ Furthermore, distal type vasospasm presents difficulty in diagnosis by TCD. In these cases, false negative may occur due to a lack of strict accuracy of TCD value. It is necessary to compare sequential magnetic resonance angiography or CT angiography with TCD, and to examine the correlation to cover the weak point of TCD.

Second, the Lindegaard index (ratio of blood flow velocities in the MCA and internal carotid artery) could not be calculated because we did not routinely perform internal carotid artery MFV measurements. The Lindegaard index has been reported to predict SVS in small patient series. ${ }^{14,17,20)}$ Finally, patients with posterior circulation aneurysms were excluded from this study. However, those patients are not likely to suffer from SVS, ${ }^{26)}$ so the influence is small in this study.

Based on the results of this study, we determined a treatment strategy for vasospasm. In patients with a MFV of $\mathrm{M}_{1} 72.5 \mathrm{~cm} / \mathrm{sec}$ or more on day 3, we intensified triple-H therapy (hypertension, hypervolemia, and hemodilution) and increased the number of TCD measurements. Furthermore, when we detected the rise of MFV, we performed angiography in an early stage of SAH within day 7 and performed the intra-arterial injection of fasudil hydrochloride, even if the patient was asymptomatic. We suggest that most cases of SVS may be prevented using this treatment strategy.

Increased MFV of $\mathrm{M}_{1}$ during the early stage of SAH may predict the future occurrence of SVS. The threshold value that appears to be predictive of SVS is a $\mathrm{MFV}$ of $\mathrm{M}_{1} 72.5 \mathrm{~cm} / \mathrm{sec}$ on SAH day 3. To prevent delayed cerebral ischemia, aggressive treatment for vasospasm is needed in patients with increased MFV during the early stage of SAH.

\section{Conflicts of Interest Disclosure}

We certify that there is no conflict of interest with any financial and personal relationships with other people or organizations regarding the material discussed in the manuscript. All authors have registered online Self-reported COI Disclosure Statement Forms through the website for JNS members.

\section{References}

1) Aaslid R, Huber $P$, Nornes $H$ : Evaluation of cerebrovascular spasm with transcranial Doppler ultrasound. J Neurosurg 60: 37-41, 1984

2) Aaslid R, Huber P, Nornes H: A transcranial Doppler method in the evaluation of cerebrovascular spasm. Neuroradiology 28: 11-16, 1986

3) Budohoski KP, Czosnyka M, Smielewski P, Kasprowicz M, Helmy A, Bulters D, Pickard JD, Kir- 
kpatrick PJ: Impairment of cerebral autoregulation predicts delayed cerebral ischemia after subarachnoid hemorrhage: a prospective observational study. Stroke 43: 3230-3237, 2012

4) Charpentier C, Audibert G, Guillemin F, Civit T, Ducrocq X, Bracard S, Hepner H, Picard L, Laxenaire MC: Multivariate analysis of predictors of cerebral vasospasm occurrence after aneurysmal subarachnoid hemorrhage. Stroke 30: 1402-1408, 1999

5) Crowley RW, Medel R, Dumont AS, Ilodigwe D, Kassell NF, Mayer SA, Ruefenacht D, Schmiedek P, Weidauer S, Pasqualin A, Macdonald RL: Angiographic vasospasm is strongly correlated with cerebral infarction after subarachnoid hemorrhage. Stroke 42: 919-923, 2011

6) Dorsch NW, King MT: A review of cerebral vasospasm in aneurysmal subarachnoid hemorrhage, part 1: Incidence and effects. J Clin Neurosci 1: 19-26, 1994

7) Findlay JM, Kassell NF, Weir BK, Haley EC Jr, Kongable G, Germanson T, Truskowski L, Alves WM, Holness RO, Knuckey NW, Yonas H, Steinberg GK, West M, Winn HR, Ferguson G: A randomized trial of intraoperative, intracisternal tissue plasminogen activator for the prevention of vasospasm. Neurosurgery 37: 168-178, 1995

8) Fountas KN, Tasiou A, Kapsalaki EZ, Paterakis KN, Grigorian AA, Lee GP, Robinson JS Jr: Serum and cerebrospinal fluid C-reactive protein levels as predictors of vasospasm in aneurysmal subarachnoid hemorrhage. Clinical article. Neurosurg Focus 26(5): E22, 2009

9) Grosset DG, Straiton J, McDonald I, Bullock R: Angiographic and Doppler diagnosis of cerebral artery vasospasm following subarachnoid haemorrhage. $\mathrm{Br}$ J Neurosurg 7: 291-298, 1993

10) Hirashima $Y$, Hamada $H$, Kurimoto M, Origasa $H$, Endo S: Decrease in platelet count as an independent risk factor for symptomatic vasospasm following aneurysmal subarachnoid hemorrhage. J Neurosurg 102: 882-887, 2005

11) Ibrahim GM, Macdonald RL: Electrocardiographic changes predict angiographic vasospasm after aneurysmal subarachnoid hemorrhage. Stroke 43: 2102-2107, 2012

12) Kassell NF, Haley EC Jr, Apperson-Hansen C, Alves WM: Randomized, double- blind vehicle-controlled trial of tirilazad mesylate in patients with aneurysmal subarachnoid hemorrhage: A cooperative study in Europe, Australia, and New Zealand. J Neurosurg 84: 221-228, 1996

13) Kincaid MS, Souter MJ, Treggiari MM, Yanez ND, Moore A, Lam AM: Accuracy of transcranial Doppler ultrasonography and single-photon emission computed tomography in the diagnosis of angiographically demonstrated cerebral vasospasm. J Neurosurg 110: 67-72, 2009

14) Klingelhöfer J, Dander D, Holzgraefe M, Bischoff C,
Conrad B: Cerebral vasospasm evaluated by transcranial Doppler ultrasonography at different intracranial pressure. J Neurosurg 75: 752-758, 1991

15) Krejza J, Swiat M, Pawlak MA, Oszkinis G, Weigele J, Hurst RW, Kasner S: Suitability of temporal bone acoustic window: conventional TCD versus transcranial color-coded duplex sonography. J Neuroimaging 17: 311-314, 2007

16) Leffers AM, Wagner A: Neurologic complications of cerebral angiography. A retrospective study of complication rate and patient risk factors. Acta Radiol 41: 204-210, 2000

17) Lindegaard KF, Nornes H, Bakke SJ, Sorteberg W, Nakstad P: Cerebral vasospasm diagnosis by means of angiography and blood velocity measurements. Acta Neurochir (Wien) 100: 12-24, 1989

18) Lysakowski C, Walder B, Costanza MC, Tramèr MR: Transcranial Doppler versus angiography in patients with vasospasm due to a ruptured cerebral aneurysm: A systematic review. Stroke 32: 2292-2298, 2001

19) Magge SN, Chen HI, Ramakrishna R, Cen L, Chen Z, Elliott JP, Winn HR, Le Roux PD: Association of a younger age with an increased risk of angiographic and symptomatic vasospasms following subarachnoid hemorrhage. J Neurosurg 112: 1208-1215, 2010

20) Naval NS, Thomas CE, Urrutia VC: Relative changes in flow velocities in vasospasm after subarachnoid hemorrhage: A transcranial Doppler study. Neurocrit Care 2: 133-140, 2005

21) Rabinstein AA, Friedman JA, Weigand SD, McClelland RL, Fulgham JR, Manno EM, Atkinson JL, Wijdicks EF: Predictors of cerebral infarction in aneurysmal subarachnoid hemorrhage. Stroke 35: 1862-1866, 2004

22) Reilly C, Amidei C, Tolentino J, Jahromi BS, Macdonald RL: Clot volume and clearance rate as independent predictors of vasospasm after aneurysmal subarachnoid hemorrhage. J Neurosurg 101: 255-261, 2004

23) Sarrafzadeh A, Haux D, Sakowitz O, Benndorf G, Herzog H, Kuechler I, Unterberg A: Acute focal neurological deficits in aneurysmal subarachnoid hemorrhage: Relation of clinical course, CT findings, and metabolite abnormalities monitored with bedside microdialysis. Stroke 34: 1382-1388, 2003

24) Seiler RW, Grolimund P, Aaslid R, Huber P, Nornes $\mathrm{H}$ : Cerebral vasospasm evaluated by transcranial ultrasound correlated with clinical grade and CTvisualized subarachnoid hemorrhage. J Neurosurg 64: 594-600, 1986

25) Serrador JM, Picot PA, Rutt BK, Shoemaker JK, Bondar RL: MRI measures of middle cerebral artery diameter in conscious humans during simulated orthostasis. Stroke 31: 672-678, 2000

26) Sloan MA, Burch CM, Wozniak MA, Rothman MI, Rigamonti D, Permutt T, Numaguchi Y: Transcranial Doppler detection of vertebrobasilar vasospasm fol- 
lowing subarachnoid hemorrhage. Stroke 25: 21872197, 1994

27) Sloan MA, Haley EC Jr, Kassell NF, Henry ML, Stewart SR, Beskin RR, Sevilla EA, Torner JC: Sensitivity and specificity of transcranial Doppler ultrasonography in the diagnosis of vasospasm following subarachnoid hemorrhage. Neurology 39: 1514-1518, 1989

28) Suarez JI, Qureshi AI, Yahia AB, Parekh PD, Tamargo RJ, Williams MA, Ulatowski JA, Hanley DF, Razumovsky AY: Symptomatic vasospasm diagnosis after subarachnoid hemorrhage: Evaluation of transcranial Doppler ultrasound and cerebral angiography as related to compromised vascular distribution. Crit Care Med 30: 1348-1355, 2002

29) Testai FD, Aiyagari V, Hillmann M, Amin-Hanjani S, Dawson G, Gorelick P: Proof of concept: endogenous antiangiogenic factors predict the occurrence of symptomatic vasospasm post subarachnoid hemorrhage. Neurocrit Care 15: 416-420, 2011

30) Udoetuk JD, Stiefel MF, Hurst RW, Weigele JB, LeRoux PD: Admission angiographic cerebral circulation time may predict subsequent angiographic vasospasm after aneurysmal subarachnoid hemorrhage. Neurosurgery 61: 1152-1161, 2007

31) Valdueza JM, Balzer JO, Villringer A, Vogl TJ, Kutter R, Einhäupl KM: Changes in blood flow velocity and diameter of the middle cerebral artery during hyperventilation: assessment with $\mathrm{MR}$ and transcranial Doppler sonography. AJNR Am J Neuroradiol 18: 1929-1934, 1997

32) van Gijn J, Kerr RS, Rinkel GJ: Subarachnoid haemorrhage. Lancet 369: 306-318, 2007

33) Vora YY, Suarez-Almazor M, Steinke DE, Martin ML, Findlay JM: Role of transcranial Doppler monitoring in the diagnosis of cerebral vasospasm after subarachnoid hemorrhage. Neurosurgery 44: 1237-1248, 1999

34) Wilson DA, Nakaji P, Abla AA, Uschold TD, Fusco DJ, Oppenlander ME, Albuquerque FC, McDougall CG, Zabramski JM, Spetzler RF: A simple and quantitative method to predict symptomatic vasospasm after subarachnoid hemorrhage based on computed tomography: beyond the Fisher scale. Neurosurgery 71: 869-875, 2012

Address reprint requests to: Hiroyuki Toi, MD, Department of Neurosurgery, Kawasaki Medical School, 577 Matsushima, Kurashiki, Okayama 701-0192, Japan. e-mail: ht11251974@yahoo.co.jp 